East African Medical Journal Vol. 77 No. 10 October 2000

RETINOPATHY OF PREMATURITY IN INFANTS WITH BIRTH WEIGHT ABOVE 1500 GRAMS

M. Al-Essa, MD, MRCPCH (UK), DCH, Department of Paediatrics, Faculty of Medicine, Kuwait University, N. Rashwan, MD, DCH, Department of Neonatology,

Maternity Hospital, Kuwait and M. Al-Ajmi, MD, FRCS, FRC (Ophth), Department of Opththalmology, Ibn Sina Hospital, Kuwait.

Request for reprints to: Dr. M. Al-Essa, Department of Paediatrics, Faculty of Medicine, Kuwait University, P.O. Box 24923-13110, Safat, Kuwait.

\title{
RETINOPATHY OF PREMATURITY IN INFANTS WITH BIRTH WEIGHT ABOVE 1500 GRAMS
}

\author{
M. AL-ESSA, N. RASHWAN and M. AL-AJMI
}

\begin{abstract}
Objective: To identify the rate and prognosis of retinopathy of prematurity (ROP) among newborn infants of birthweight of above 1500 grams, and the possible risk factors associated with the disease.

Design: A prospective cohort study.

Setting: Neonatal unit at Maternity Hospital, Kuwait city, Kuwait.

Methods: All low birth weight infants were examined for the presence of ROP in the period between January 1996 to December 1997. Prospective collection of data on babies who were above 1500 grams was done to find an association between the disease in these babies and some of the maternal and neonatal risk factors.

Results: A total of 68 babies of birth weight above 1500 grams were screened for ROP out of which $13(19.1 \%)$ had different stages of the disease. None of the patients had threshold disease requiring surgery. Among the risk factors chosen, oxygen therapy, presence of hypotension at birth and the non-use of surfactant were the only risk factors to be associated with disease. However, with logistic regression analysis, none of these were independently associated with ROP.

Conclusion: ROP may occur in newborn infants of larger birthweight but with good prognosis, and oxygen therapy seems to predispose to the disease.
\end{abstract}

\section{INTRODUCTION}

Retinopathy of prematurity (ROP) is a disorder of blood vessels in the developing retina of the premature infants(1-3), and is one of the important causes of blindness and impaired vision among children $(2,4)$. The incidence varies in different neonatal units(5-7) and low birth weight has been the only risk factor uniformly identified(5-14). However, the disease may occur in the larger birth weight babies but with no information about the prognosis and the risk factors associated with it $(10,15)$. We report the incidence of ROP in a cohort of babies of birth weight above 1500 grams with the possible risk factors and the prognosis of the disease in this group of babies.

\section{MATERIALS AND METHODS}

We screened all infants admitted to the neonatal unit at Maternity Hospital and of gestational age below 34 weeks in the period between January 1996 and December 1997. The screening was performed by the ophthalmologist using indirect ophthalmoscope after dilating the pupils of the babies by $2.5 \%$ phenylephrine and $0.5 \%$ tropicamide eye drops instilled into each eye three times at intervals of 15 minutes prior to examination. We followed the protocol of examining preterm infants at four weeks of postnatal age and/or at 32 weeks corrected age, and those above 32 weeks gestation were examined in the first week of birth. If no ROP was detected at the initial examination, the infants were re-evaluated once every two weeks until discharge and then every four weeks until three months of corrected age. If
ROP was detected, the examinations were performed every week till the disease started to regress. The changes of ROP were classified according to the International Classification of Retinopathy of Prematurity(14).

The data of patients were collected prospectively. The following neonatal risk factors were considered: birth weight, gestational age, Apgar score of less than 5 at five minutes and oxygen therapy which was defined as the maximum fractional inspired oxygen $(\mathrm{FiO} 2)$ needed by the baby to keep the oxygen saturation above $91 \%$ for more than 24 hours. In addition, surfactant therapy (Survanta ${ }^{\circledR}$ ); presence of anaemia or hypotension at birth and reception of blood transfusion in the first 24 hours, the total number of blood transfusions received during the hospital stay, phototherapy, total parentral nutrition, presence of patent ductus arteriosus, intraventricular haemorrhage, apnoea, proven sepsis and undergoing abdominal surgery were also considered.

Furthermore, the following maternal risk factors were also considered: gestational or maternal diabetes, gestational or maternal hypertension, antepartum haemorrhage, chorioamnionitis and premature rupture of membranes. The data were then entered in the SSPS database software and analysed statistically using Student t-test for continuous variables and Chi-square test for categorical variables(16). Stepwise logistic regression analysis was used to determine the predictors associated with the development of the disease(17).

\section{RESULTS}

Three hundreds and two babies were screened for ROP over the two years out of which sixty eight were of birth 
weight above 1500 grams. The mean birth weight was $1768 \pm 188.5$ grams (range 1530-2460). There were 41 males and 27 females, 40 singletons, eight sets of twins and four sets of triplets. There were no deaths. The overall number of documented ROP among all babies in our unit is 164 $(54.3 \%)$. In those above 1500 grams the total number was $13(19.1 \%)$, and in all the disease was in both eyes. Two of the cases were of stage three but did not reach threshold point and the disease has regressed. Among the risk factors defined only maximum fractional inspired oxygen ( $\mathrm{FiO} 2)$, presence of hypotension at birth and the non-use of surfactant were significantly associated with the disease.

Table 1

Neonatal risk factors associated with ROP

\begin{tabular}{|c|c|c|c|}
\hline & $\operatorname{ROP}(n=13)$ & No ROP $(n=55)$ & $\mathrm{p}$ value \\
\hline $\begin{array}{l}\text { Birth weight in grams } \\
\text { Mean } \pm \text { SD }\end{array}$ & $1695.4 \pm 164$ & $1785 \pm 213$ & 0.16 \\
\hline $\begin{array}{l}\text { Oxygen } \mathrm{FiO} 2(\%) \\
\text { Mean } \pm \mathrm{SD}\end{array}$ & $50.38 \pm 11.08$ & $43.09 \pm 8.02$ & 0.008 \\
\hline $\begin{array}{l}\text { Presence of patent } \\
\text { ductus arteriosus }\end{array}$ & $4(30.8 \%)$ & $6(11 \%)$ & 0.09 \\
\hline $\begin{array}{l}\text { Presence of intra- } \\
\text { ventricular hemorrhage }\end{array}$ & $1(7.7 \%)$ & $4(7.3 \%)$ & 0.67 \\
\hline $\begin{array}{l}\text { Blood transfusion in the } \\
\text { first } 24 \text { hours }\end{array}$ & $4(30.8 \%)$ & $6(11 \%)$ & 0.09 \\
\hline Surfactant therapy & $5(38.5 \%)$ & $6(11 \%)$ & 0.03 \\
\hline Phototherapy & $9(69.2 \%)$ & $22(40 \%)$ & 0.055 \\
\hline Apnoea & $3(23 \%)$ & $5(9.1 \%)$ & 0.17 \\
\hline Apgar score $<5$ at $5 \mathrm{~min}$ & $3(23 \%)$ & $14(25.5 \%)$ & 0.58 \\
\hline Proven sepsis & $4(30.8 \%)$ & $6(8.8 \%)$ & 0.09 \\
\hline Undergone surgery & $1(7.7 \%)$ & $1(1.8 \%)$ & 0.35 \\
\hline $\begin{array}{l}\text { Total parentral nutrition } \\
\text { Number of blood }\end{array}$ & $6(46.2 \%)$ & $16(29.1 \%)$ & 0.2 \\
\hline transfusion $($ mean $\pm \mathrm{SD})$ & $1.85 \pm 2.51$ & $0.91 \pm 1.87$ & 0.13 \\
\hline Presence of anemia at birth & $3(23 \%)$ & $7(12.7 \%)$ & 0.39 \\
\hline $\begin{array}{l}\text { Presence of hypotension } \\
\text { at birth }\end{array}$ & $4(30.8 \%)$ & $4(7.3 \%)$ & 0.038 \\
\hline
\end{tabular}

Table 2

Maternal risk factors associated with ROP

\begin{tabular}{lrrr}
\hline & ROP $(\mathrm{n}=13)$ & No ROP $(\mathrm{n}=55)$ & $\mathrm{p}$ value \\
\hline Antepartum haemorrhage & $2(15.4 \%)$ & $7(12.7 \%)$ & 0.55 \\
Chorioamnionitis & $1(7.7 \%)$ & $1(1.8 \%)$ & 0.8 \\
Gestational diabetes & $2(15.4 \%)$ & $4(7.3 \%)$ & 0.67 \\
Maternal hypertension & $1(7.7 \%)$ & $14(25.5 \%)$ & 0.15 \\
Premature rupture of & & & \\
membranes & $5(38.5 \%)$ & $5(9.1 \%)$ & 0.33 \\
& & & \\
\end{tabular}

Tables 1 and 2 respectively show the neonatal and maternal risk factors associated with the disease. After stepwise logistic regression analysis none of these factors was an independent predictor of the disease.

\section{DISCUSSION}

Retinopathy of prematurity is the disease of low birth weight as it is the definite risk factor established in all studies of this matter(1,4-8,14). Neonatal units have different prevalence of the disease. This possibly depends on the examining ophthalmologist in identifying the disease and its stages and the guidelines for screening and treatment(18).

Our disease prevalence was $54.3 \%$ which is different from some of the units in the region; in Oman is 34\%, and in a centre in India was $20 \%(5,6)$. However, none of these centres reported the prevalence of the disease in those babies above 1500 grams. Jandeck et al (15) reported the occurrence of ROP in three babies of birth weight above 2000 grams after haemorrhagic shock. In their study, they screened 123 babies of above 1500 grams and apart from the three shocked babies, none of the rest developed any stage of the disease. One of the three babies required cryotherapy after the disease reached a threshold stage. No other risk factors were identified to be associated with the disease and they concluded that severe haemorrhagic shock could be a risk factor for the development of ROP even in large babies. Our study reported the occurrence of the disease in the babies of birth weight above 1500 grams in a rate of $19.1 \%$, but none of them reached threshold stage and all have the disease regressed(19). No risk factors were independently associated with the disease although oxygen therapy tended to be a likely risk factor. We did not have any baby who was exposed to severe circulatory shock. Holmstrom et al(11) assessed maternal risk factors associated with ROPI. They found That essential hypertension prior to pregnancy was a predicting risk factor. In our study, a univariate analysis of the maternal risk factors revealed that none was associated with the ROP although our babies were larger in weight.

So we concluded that ROP does occur in babies of birth weight more than 1500 grams but in mild form and with good prognosis, and screening in this group of babies is not warranted and should be limited to very low and the extremely low birth weight babies.

\section{REFERENCES}

1. Bossi E. and Koerner F. Retinopathy of prematurity. Intensive Care Med. 1995; 21: 241 -246.

2. Flynn J.T. Retinopathy of prematurity: Perspective for the nineties. Acta Ophthalmol. Scand. (Suppl) 1995; 214: 12-14.

3. Fledelius H.C. Pre-term delivery and subsequent ocular development. Acta Ophthalmol. Scand. 1996; 74:288-293.

4. Ng Y.K., Fielder A.R., Shaw D.E. and Levene M.I. Epidemiology of retinopathy of prematurity. Lancet 1988; 2:1235-1238.

5. Bassiouny M.R. Risk factors associated with retinopathy of prematurity: A study from Oman. J. trop. Paediat. 1996; 42: 335 358 .

6. Maheshwari R., Kumar H., Paul V.K., Singh M., Deorari A.K. and Tiwari H.K. Incidence and risk factors of retinopathy of prematurity in a tertiary care newborn unit in New Delhi. National Med. J. India 1996; 9: 211-214.

7. Charan R., Dogra M.R., Gupta A. and Naarang A. The incidence of retinopathy of prematurity in a neonatal care unit. Indian $J$. Ophthalmol. 1995; 43: 123-126.

8. Teoh S.L., Boo N.Y., Ong L.C., Nyein M.K., Lye M.S. and Au M.K. Duration of oxygen therapy and exchange transfusion as risk 
factors associated with retinopathy of prematurity in very low birthweight infants. Eye 1995; 9: 733-737.

9. McKibbin M. and Dabbs T.R. Assisted conception and retinopathy of prematurity. Eye 1996;10: 476-478.

10. Fledelius H C: Central nervous system damage and retinopathy of prematurity-an ophthalmic follow-up of prematures born in 198284. Acta Paediat. 1996; 85: 1186-91.

11. Holmstrom G., Thomassen P. and Broberger U. Maternal risk factors for retinopathy of prematurity - a population-based study. Acta Obstet. Gynec. Scand. 1996; 65: 628-635.

12. Cunningham S., Fleck, Elton R.A. and McIntosh N. Transcutaneous oxygen levels in retinopathy of prematurity.Lancet 1995;346:14641465 .

13. Blumenfeld L.C., Siatkowski M., Johnson R.A., Feuer W.J. and Flynn J. Retinopathy of prematurity in multiple gestation pregnancies. Amer. J. Ophthalmol. 1998; 125:197-203.
14. Cryotherapy for Retinopathy of Prematurity Cooperative Group: Multicenter trial of cryotherapy for retinopathy of prematurity; preliminary results. Arch. Ophthalmol. 1988; 106: 471-479.

15. Jandeck C., Kellner U., Kossel H., Bartsch M., Versmold H.T. and Froester H. Retinopathy of prematurity in infants of birth weight $>2000 \mathrm{~g}$ after haemorrhagic shock at birth. Brit. J. Ophthalmol. 1996; 80:728-731

16. Scott S.C., Goldberg M.S. and Mayo N.E. Statistical assessment of ordinal outcomes in comparative studies. J. Clin. Epidem. 1997; 50: $45-55$.

17. Ludbrook J. Comparing methods of measurement. Clin. Exp. Pharmacol. Physiol. 1997; 24: 193-203.

18. Retinopathy of prematurity: guidelines for screening and treatment; The report of a Joint Working Party of The Royal College of Ophthalmology and the British Association of Perinatal Medicine. Early Human Development 1996; 46: 239-258.

19. Preslan M.W. and Butler J. Regression pattern in retinopathy of prematurity. J Paediat. Ophthalmol. Strabismus 1994; 31: 172176.

Letter to the Editor-in-Chief

Dear Sir,

\section{RE: THE VERY HIGH MATERNAL MORTALITY RATIOS: HOW REAL?}

Maternal mortality ratio is a proxy for the more accurate maternal mortality rate, since measuring all pregnancies in a population, as expected in maternal mortality rate is neither feasible nor practicable.

Maternal mortality ratio is calculated by dividing the number of maternal deaths regardless of pregnancy outcome (ectopic pregnancy, foetal deaths, livebirths) by the number of livebirths in a defined population(1).

Institution-based maternal mortality ratios, especially from the developing countries appear to be scandalously high(2-5). Is this a true reflection of events or some statistical artifact?

A few salient points might provide the correct answer. For instance, it is common practice in some parts of Nigeria for pregnant mothers to elect home delivery even when they have had antenatal care in the hospital. This inadvertently lowers the denominator, in the calculation for maternal mortality ratio for the health institution

Paradoxically, in the same community, within the same period, some pregnant mothers might be brought to the hospital for the first time only when they are in moribund state (at times gasping for the last breath), following pregnancy or labour complications. To such patients, the hospital is more of a mortuary than a maternity centre, thus increasing the number of maternal deaths for the institution. It is therefore easy to understand why some institutional maternal mortality ratios are high - at times too high to be real.

There is yet another mathematical dimension to the issue. Because of the less than satisfactory prenatal and intrapartum care that pregnant mothers receive in most of the developing countries, there are more cases of foetal deaths or stillbirths than what obtains in the advanced, western nations. As a result, while live births almost approximate to total births in the developed countries, the difference between the two in the developing countries could be enormous. However, since maternal mortality ratio is calculated using live births as denominator, the relatively small live births (as opposed to total births) in the developing countries will inevitably lead to an outrageously high maternal mortality ratio. In fact, most authors from the developing countries would rather prefer to calculate maternal mortality rate using total deliveries as the denominator $(6,7)$ instead of livebirths, perhaps to minimise these artifacts.

Again, let us not miss the point! In sub-Saharan Africa, the time risk that a woman would die in childbirth is 1 in 21 ; which is times higher than the lifetime risk for her counterpart in Western Europe or North America. It is an undisputed fact that there are too many avoidable maternal deaths in the developing or impoverished countries. My humble submission however, is that unless we recognise some of these arithmetic errors and statistical artifacts in institution-based maternal mortality reports, especially those emanating from the developing countries, we might soon conclude erroneously that there are no women of reproductive age in the third world countries anymore, because of the toll of maternal mortality. That we know is not true! We must therefore interpret figures on maternal deaths from developing countries with caution.

Yours sincerely

B. Ekele, MBBS, FWACS, FICS, Senior Lecturer/Consultant Obstetrician, Department of Obstetrics and Gynaecology, Usmanu Danfodiyo University Teaching Hospital, Sokoto, Nigeria.

\section{REFERENCES}

1. World Health Organisation. An epidemiologic approach to reproductive health. Geneva. WHO, 1994.

2. Agbogoroma O. C. and Emuveyan E. E. Maternal mortality in Lagos, Nigeria: A ten year review (1986-1995), Nig. Quart. J. Hosp. Med. 1997; 7:230-233.

3. Audu L. R. and Ekele B. A. Maternal Mortality at the Usmanu Danfodiyo University Teaching Hospital, Sokoto, Nigeria. Proceedings of 5th International Conference, Society of Obstetrics and Gynaecology of Nigeria (SOGON), Benin, Nigeria, 1998.

4. Ujah I. A., Uguru V. E., Aisien A. O., Sagay A. S. and Otubu J. A. How safe is motherhood in Nigeria? the trend of maternal mortality in a tertiary health institution. East Afr. Med. J. 1999; 76:436-9.

5. Ahmed Y., Mwaba P., Chintu C., Grange J. M., Ustianowski A. and Zumla A. A study of maternal mortality at the university teaching hospital, Lusaka, Zambia: the emergence of tuberculosis a major nonobstetric cause of maternal death. Int. J. Tuberc. Lung Dis. 1999; 3: 675-80

6. Harrison K. A. Child-bearing, Health and Social Priorities: A survey of 22,774 consecutive Hospital births in Zaria, Northern Nigeria. Brit. J. Obstet. Gynaecol. 1985; suppl 5:100-115.

7. Adetoro O. O. Maternal Mortality. A 12 years survey of the University of Ilorin Teaching Hospital, Ilorin, Nigeria. Int .J. Gynec. Obstet. 1987; 25:93-98. 